Correction

\title{
Correction: Marslin, G., et al. Secondary Metabolites in the Green Synthesis of Metallic Nanoparticles. Materials 2018, 11, 940
}

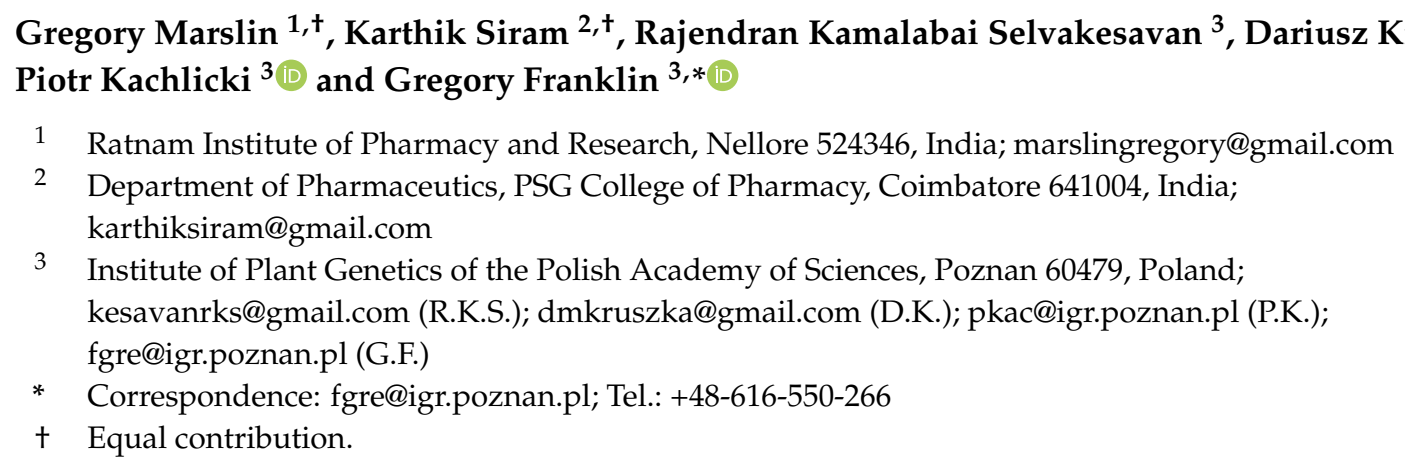

Received: 5 March 2019; Accepted: 7 March 2019; Published: 8 March 2019

The authors have overlooked a few mistakes when rearranging the Tables 1 and 2 and references at the final stages, which were carried-over to the published version of the review. Consequently the authors wish to make at this time the following corrections to the paper [1]:

Table 1. Plant components possibly involved in the green synthesis of nanoparticles (NPs) from various plant species.

\begin{tabular}{cclc}
\hline Plant Species & NPs & \multicolumn{1}{c}{ Metabolites Identified in the Extract/NPs } & Reference \\
\hline Ocimum sanctum & $\mathrm{Ag}$ & Eugenols, linalool, terpenes & {$[49]$} \\
Helianthus annuus & $\mathrm{Ag}$ & Fatty acids, triglycerides, phenolics, tocopherols & {$[54]$} \\
Solanum xanthocarpum & $\mathrm{Ag}$ & Alcohols, phenols, carboxylic anions & {$[67]$} \\
Morinda pubescens & $\mathrm{Ag}$ & Flavonoids, triterpenoids, polyphenols & {$[71]$} \\
Carica papaya & $\mathrm{Ag}$ & Proteins, alcohols, phenolics & {$[72]$} \\
Piper betle & $\mathrm{Ag}$ & Amide, aromatic amine & {$[84]$} \\
Eucalyptus & $\mathrm{Fe}$ & Alcohol, phenols, alkylaldehyde & {$[81]$} \\
\hline
\end{tabular}

Table 2. Bioactivities of green-synthesized NPs.

\begin{tabular}{llcc}
\hline NPs & Plant Species Used & Bioactivity Reported & Reference \\
\hline $\mathrm{Ag}$ & Lansium domesticum & Antibacterial & {$[104]$} \\
\hline
\end{tabular}

Page 11, final paragraph: Citation [208] should be read as [218].

\section{References}

70. Geethalakshmi, R.; Sarada, D.V. Synthesis of plant-mediated silver nanoparticles using Trianthema decandra extract and evaluation of their antimicrobial activities. Int. J. Eng. Sci. Technol. 2010, 2, 970-975.

111. Correa, S.N.; Naranjo, A.M.; Herrera; A.P. Biosynthesis and characterization of gold nanoparticles using extracts of Tamarindus indica L Leaves. J. Phys.: Conf. Ser. 2016, 687, 012082.

225. Shah, M.; Fawcett, D.; Sharma, S.; Tripathy, S.K.; Poinern, G.E.J. Green synthesis of metallic nanoparticles via biological entities. Materials 2015, 8, 7278-7308. 
The manuscript will be updated and the original will remain available on the article webpage. We would like to apologize for any inconvenience caused to the readers.

\section{References}

1. Marslin, G.; Siram, K.; Maqbool, Q.; Selvakesavan, R.; Kruszka, D.; Kachlicki, P.; Franklin, G. Secondary metabolites in the green synthesis of metallic nanoparticles. Materials 2018, 11, 940. [CrossRef] 